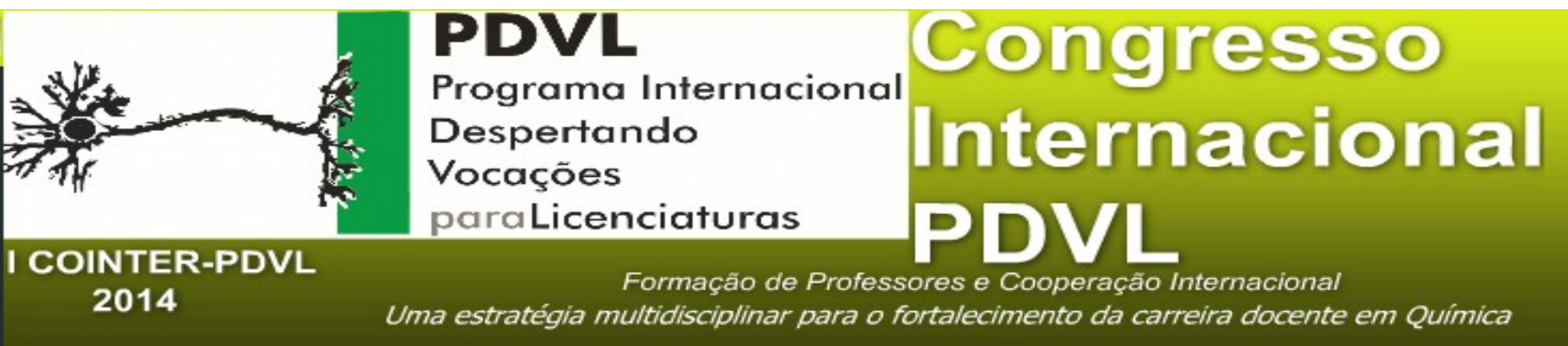

\title{
FORNO SOLAR À BAIXO CUSTO: UM ESTUDO EXPERIMENTAL E INTERTIDISCIPLINAR
}

\author{
Apresentação: Comunicação Oral
}

\begin{abstract}
Jefferson Augusto de Oliveira Galindoㅜㅜ Gizele das Graças Farias de Andrade²; Jandrews Lins Gomes;
\end{abstract}

\begin{abstract}
Resumo
O ensino de modo experimental e interdisciplinar vem sendo tema muito frequente em discussões recentes quanto à qualidade e efetividade do ensino, pincipalmente quando tratamos do ensino a nível médio, que por muitas vezes sofre com a falta de ligação entre suas diversas disciplinas, o que acaba por dar pouco sentido aos conceitos trabalhados em sala de aula apenas de modo teórico. O trabalho a seguir apresenta resultados de uma intervenção pedagógica realizada em uma turma do $2^{\circ}$ ano do ensino médio de uma escola localizada no interior de Pernambuco. A pesquisa teve como objetivo principal trabalhar experimentalmente alguns dos conceitos relacionados à termodinâmica, principalmente à parte relativa temperatura e trocas de calor a partir de uma visão interdisciplinar. Nesse caso, optou-se por trabalhar esses conceitos a partir de análises físicas e químicas que podem ser feitas facilmente utilizando o forno solar, que foi confeccionado a partir de materiais de baixo custo. Além disso, o trabalho propõe e analisa a importância da experimentação no ensino das ciências a partir de estudos relativos ao tema e por fim, conclui-se com esse trabalho que podemos
\end{abstract}

1 Licenciatura em Física/ IFPE - Campus Pesqueira/ jefferson.a.galindo@gmail.com² Licenciatura em Física/ IFPE -

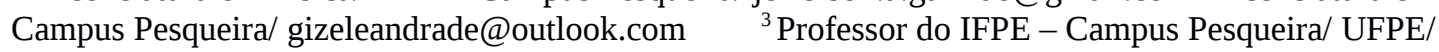
jandrewsgomes@gmail.com 
dar uma resposta positiva quando somos questionados quanto à possibilidade do ensino experimental e interdisciplinar.

Palavras-Chave: Experimentação, Interdisciplinaridade, ensino de ciências.

\section{Introdução}

Atualmente, podemos perceber alguns motivos pelos quais a escola necessita de alguma reforma em suas bases, por exemplo, segundo Rocha e Filho et al. (2007) quando a escola se torna incapaz de se renovar, de modificar suas bases ela estaciona nos métodos classicistas de ensino e acabam por eliminar toda a capacidade, competência e autonomia individual dos alunos, se mantendo estagnada no autoritarismo. O autor nos fala o quanto estamos parados quanto às metodologias que estão se limitando ao "fazer automático”, não se estendendo, não buscando a formação voltada ao "pensar” e ao “como pensar” que são partes fundamentais da autonomia e da capacidade de cada indivíduo.

Esse trabalho exibe resultados de uma intervenção pedagógica com caráter experimental aplicadas em uma turma do $2^{\circ}$ ano do ensino médio da escola pública Estadual Gonçalo Antunes Bezerra, situada como extensão na escola Municipal José Paes Gramim localizada no bairro de Perpétuo Socorro, distrito do município de Alagoinha, interior de Pernambuco, com uma visão interdisciplinar, utilizando um forno solar construído a partir de materiais recicláveis, relacionando a importância da experimentação no ensino de ciências (ARAÚJO E ABIB, 2009; BORGES 2002; MATOS E VALADARES, 2001; ROSA E RAMOS, 2008; VILLANI E NASCIMENTO, 2003; ZANON E SILVA, 2009) e visualizando alguns itens que podem ser trabalhados em um contexto interdisciplinar (DOS SANTOS, 2011; FAZENDA, 2003; FOUREZ, 1995; LENOIR, 1998; POMBO, 1993), em algumas análises que cabem tanto a física quanto a química envolvidas na experimentação e se há ou não possibilidade de se trabalhar dessa forma ao nível de ensino médio.

\section{O Papel da experimentação no Ensino das Ciências}

A experimentação em geral, em termos do ensino de física, têm um papel muito importante e relevante quanto à assimilação e a aprendizagem pela prática. Uma vez que, o aluno têm se tornado uma peça cada vez mais fundamental quando são debatidos todos os assuntos pertinentes à educação, não dependendo apenas da maneira tradicional e pouco ativa do método usado pelos professores, onde o educador trata o aluno como um mero receptor do conhecimento, apto a receber 
e a armazenar tudo que lhe é exposto. Esse método pedagógico é alcunhado como sendo um modo de educação “bancária”, segundo Paulo Freire:

\footnotetext{
"A educação "bancária” pressupõe uma relação vertical entre o educador e educando. O educador é o sujeito que detêm o conhecimento, pensa e prescreve, enquanto o educando é o objeto que recebe o conhecimento, é pensado e segue a prescrição. O educador "bancário” faz "depósitos" nos educandos e estes passivamente as recebe.” (FREIRE, 1979, 1983)
}

No ensino das ciências vale ressaltar também a dificuldade da assimilação dos conteúdos devido à falta de aproveitamento dos conhecimentos prévios que o aluno obteve nas suas experiências de vida. $\mathrm{O}$ aluno que não consegue relacionar sua vivência com o que lhe está sendo transmitido sofre com dificuldades dentro de sala de aula, ele não vê nenhum sentido no que ele está aprendendo, o que torna a aprendizagem muito menos significativa. Nesse contexto entra em cena o ensino tendo caráter experimental, uma vez que o aluno envolvido com a experimentação tem mais facilidade na visualização e na construção de conteúdos como afirmam os autores Araújo e Abib:

“A experimentação tem papel fundamental no processo de construção conceitual, visto que muitas vezes é necessário “desconstruir” conceitos desenvolvidos pelo senso comum, de modo que, é imprescindível que o educando visualize a situação, observe e analise os resultados para perceber e mudar o seu pensamento, não apenas acatar o que o professor diz.” (ARAÚJO \& ABIB, 2009)

Contudo, como afirmam Zanon e Silva (apud Guimarães, 2009) o ensino de ciências pode ser muito mais significativo se conseguimos relacionar os saberes teóricos com as situações práticas presentes quando utilizamos alternativas de métodos experimentais que podem trabalhar muito satisfatoriamente essas relações intrínsecas do âmbito escolar, promovendo o ensino por vias práticas, utilizando o método experimental como uma potente ferramenta de ensino.

Em uma breve discussão com Villani e Nascimento (2003) podemos perceber que quando o aluno se depara com uma situação experimental no laboratório didático, ele consegue criar uma melhor percepção e um amplo entendimento no contexto escolar, uma vez que os alunos sentem a necessidade de argumentar, de construir conhecimentos mais amplos e complexos, se aproximando do contexto científico quando posto à prova seu conhecimento relacionado à prática vivenciada.

A falta de organização do tempo em sala de aula também pode ser um empecilho no ensino. Paulo Rosa e Luciana Ramos (2008) afirmam isso dizendo ainda que, os professores possuem um costume de separar a prática da teoria que acaba por nos manter no antigo modelo tradicional de 
ensino. E isso só pode ser alterado ou modificado com a experimentação, com a não acomodação do professor quanto ao seu método e a sua prática escolar.

Maria Goreti Matos e Jorge Valadares propõem um modelo no qual se tem por base o construtivismo, o qual se mantém firme quanto à criação de um ambiente favorável ao ensino, como pela experimentação no cotidiano do alunado. Com isso, o método de ensino experimental, se mantendo sobre a base construtivista e investigativa, pode reformular os arquétipos mentais que os alunos têm sobre determinado tema ou afirmação, construindo e solidificando a aprendizagem.

\footnotetext{
"Ele contribui não só para melhorar os conhecimentos dos alunos modificando e enriquecendo os seus modelos mentais no sentido da aproximação aos modelos compartilhados pela comunidade científica, como também para adquirirem diversas capacidades que lhes serão extremamente úteis pela vida fora.” (MATOS \& VALADARES, 2001, p. 236)
}

Com isso, podemos afirmar que o ensino da termodinâmica pode ser trabalhado de forma eficiente se feita experimentalmente, buscando a melhor interação entre a teoria e a prática o que faz com que os alunos consigam ter um melhor entendimento e uma assimilação eficaz de conteúdos relacionados à termodinâmica, como poderemos notar no decorrer desse trabalho.

\section{Metodologia}

A intervenção pedagógica foi realizada por alunos do curso de licenciatura em Física do IFPE Campus Pesqueira com alunos de uma turma do segundo ano do ensino médio, com idade entre 15 e 18 anos, de uma escola do interior de Pernambuco. Devido à localização e a falta de estrutura da escola, como por exemplo, a falta de um laboratório de física ou de ciências (não exclusividade dessa escola), foi decidida a utilização de um experimento científico como metodologia pedagógica na turma escolhida como objeto de estudo a fim de tirar os alunos da sua rotina diária.

O experimento foi confeccionado utilizando isopor, uma caixa de papelão, uma placa de ferro, um pedaço de vidro e papel alumínio. A montagem do experimento é simples: basicamente forrar a caixa de papelão internamente com isopor, depois cobrir essa parte interna com papel alumínio e colocar no interior da caixa uma placa de ferro pintada de preto. Ao fim, colocar uma tampa de vidro sobre a caixa.

Depois de realizada a montagem do experimento, conforme a Figura 1, foi posto dentro do fogão um pequeno recipiente com $50 \mathrm{ml}$ de água e aferida a temperatura inicial da água pelo 
alunado. Passado certo período de tempo foi medida a temperatura final. Logo após, foram propostas as seguintes questões: O que mudou no sistema? O que é temperatura? O que fez aumentar a temperatura da água?

Tendo realizado todo este processo, podemos fazer duas análises, uma análise física e uma química que podem ser discutidas com base na literatura e trabalhadas com os dados aferidos pelos próprios alunos.

\section{Análise Física do Experimento}

Segundo Resnick et al. (2009), a propagação do calor ocorre de três formas: condução, convecção e radiação térmica. Os três tipos de propagação de calor podem ser facilmente observados pelos alunos no experimento do fogão solar. A placa de ferro aquece dentro do fogão quando é exposto ao sol por meio de irradiação solar, ao passo que, o recipiente colocado sobre a chapa é aquecido por meio da condução térmica que aquece a água. O sistema eleva sua temperatura através da condução e da convecção, tanto na água dentro do recipiente quanto no ar dentro do fogão. É perceptível que o sistema é quase isolado do meio externo, por não permitir condução térmica entre a parte interior do fogão e suas paredes internas feitas de isopor. $\mathrm{O}$ ar dentro do sistema é impedido de sair por causa da tampa de vidro, evitando assim a troca de calor com o meio externo, além do mais, como as paredes são revestidas com papel alumínio, não é permitida a troca de calor por meio de irradiação nas laterais do fogão. O refletor posto sobre o fogão auxilia na reflexão das ondas provenientes do sol, como exposto na Figura 2. 


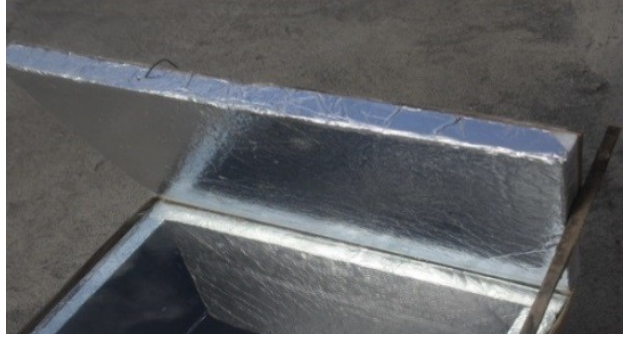

Figura 1: Fogão Solar. Fonte: Própria.

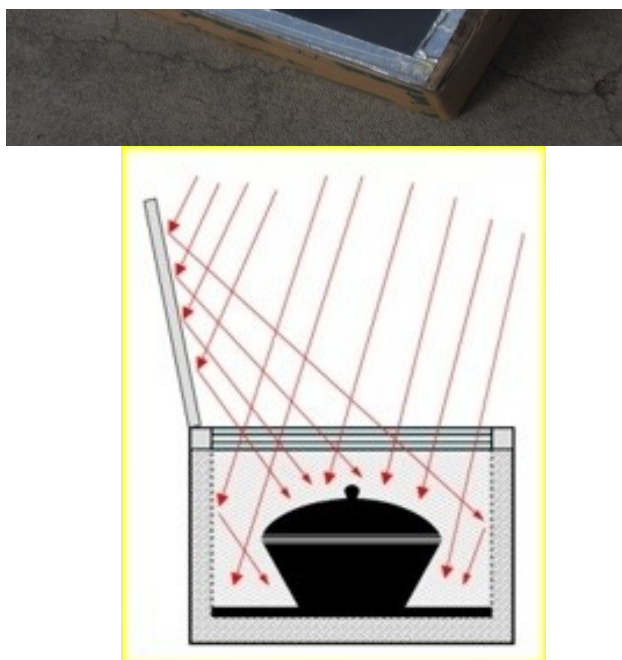

Figura 2: Ilustração da Irradiação dentro do Fogão. Fonte: sempresustentável.com.br.

Sendo assim, podemos relacionar a temperatura com a Lei zero da termodinâmica e cogitar as formas de propagação do calor aplicadas sobre o fogão solar trabalhando também os conceitos da primeira lei, temas bem relacionados pelos autores Kazuhito e Fuke (2010) no livro didático utilizado pelos alunos em sala de aula.

\section{Análise Química do Experimento}

Primeiro item que pode ser analisado quimicamente é a temperatura em uma visão microscópica, que de acordo com Eduardo Mortimer e Luiz Amaral:

“Sendo todos os materiais constituídos por moléculas, íons ou átomos, a temperatura pode ser associada à energia cinética média dessas moléculas, íons ou átomos. Em outras palavras, pode-se considerar que a temperatura expressa o maior ou menor grau de agitação térmica das moléculas de um corpo. Quanto maior a temperatura, maior será a agitação térmica dessas moléculas.” (MORTIMER \& AMARAL, 1998)

Onde segundo os mesmos fazem considerações sobre as transferências de calor em uma análise categórica.

“Quando uma fonte quente entra em contato com uma panela de alumínio, por exemplo, ela aumenta a agitação térmica e, portanto a energia cinética dos átomos da superfície do metal em contato com a fonte. Por meio de sucessivas colisões, parte da energia cinética dos átomos da região aquecida é transferida para os átomos da região vizinha e assim sucessivamente, até atingir todos os átomos da panela. Nesse processo, o calor é transmitido de átomo para átomo sem que os mesmos sofram deslocamento ao longo do 
metal. Em outras palavras, a energia é transferida sem que haja transporte de matéria. [...] O Fluxo de calor continuará enquanto existir uma diferença de temperatura.” (MORTIMER \& AMARAL, 1998)

Pudemos utilizar essa afirmação no experimento, quando observamos que a chapa de metal está em contato com o recipiente e que há uma troca de calor por meio da condução térmica. Na situação proposta aos alunos, além de podermos calcular a quantidade de calor necessário para elevar a temperatura do líquido pelos meios de propagação, também trabalhamos quimicamente esse processo. Como, por exemplo, qual é a quantidade de calor necessário para transformar $50 \mathrm{ml}$ de água a $100{ }^{\circ} \mathrm{C}$ totalmente em vapor? E qual a variação de Entalpia do processo? Em primeiro lugar, os alunos calcularam a quantidade de calor necessária para a variação de temperatura no líquido, isto ocorreu através do calor latente de vaporização da água, sendo assim, relacionaram o processo com toda a Física trabalhada em sala de aula. O resultado nos mostra um valor total de 54.000 calorias, ou aproximadamente $225 \mathrm{~kJ}$.

Para o segundo caso, relativo à Química, como temos um processo endotérmico, onde a substância recebe calor e, por consequência, energia química, os alunos utilizaram o conceito de que a entalpia de vaporização é o calor fornecido dividido pelo número de moles de uma substância para calcular a variação de entalpia necessária para ser realizado o processo. Em 50 g de água temos aproximadamente 2,78 moles da substância. Então, pode-se calcular a variação de entalpia total para esse número de moles de água, que é de aproximadamente 81 kJ.

Os conceitos estudados em sala nos permitiram estabelecer uma relação entre a entalpia e a temperatura, onde trabalhamos com a questão proposta anteriormente, o calor latente, que segundo Fernandes et al.:

\footnotetext{
"Durante a mudança de estado, conforme energia vai sendo fornecida para as moléculas a entalpia do sistema aumenta, porém a temperatura do fluido permanece constante. A temperatura do fluido só voltará a aumentar quando todas as moléculas do fluido tiverem mudado de estado.” (FERNANDES, 2006)
}

Ou seja, um experimento de simples confecção fornecer muitas alternativas de ensino, podendo ser trabalhado também a interdisciplinaridade no ensino de Física e Química em um assunto em que as duas partes da ciência entram em uníssono em suas discussões.

\section{Resultados e Discussões}

No primeiro momento ao realizar uma discussão oral, é notável que o aluno procure diversas 
formas de construir possíveis teorias para explicar o que acontece no experimento, com isso, foram anotadas com o auxílio de quadro e giz todas as considerações feitas pelos alunos para tentar aproveitar totalmente o conhecimento prévio, que é abordado de forma categórica por Piaget (1973) que enfatiza totalmente o saber do aluno, toda sua vivência e seu desenvolvimento ao entrar em contato direto com o objeto trabalhado, construindo de forma intuitiva o conhecimento científico relacionado a determinado experimento. Isto é, o aluno tenta de algum modo pensar de maneira científica, desabrochando a curiosidade acerca do experimento realizado, sendo uma ferramenta de muita utilidade para o professor. Segundo Demo (2000), no contexto da educação pela experimentação, pela pesquisa, o aluno se assume como principal responsável do processo de ensino-aprendizagem toda vez que ele se manifesta, argumenta acerca de algum assunto, com isso, ele está intencionalmente ou não, construindo o conhecimento e tirando as dúvidas possíveis com o auxílio do professor no ambiente de sala de aula, situação vivida na pele pelos alunos ao manusearem o experimento e fazer todas as aferições e medidas necessárias para a verificação do experimento. Muitas dúvidas surgiram e puderam ser esclarecidas pelos licenciandos envolvidos na intervenção. Com isso, os alunos entram no contexto da educação pela experimentação, pela curiosidade, pelo simples fato do gosto pela ciência, como exposto nas Figuras 1 e 2.

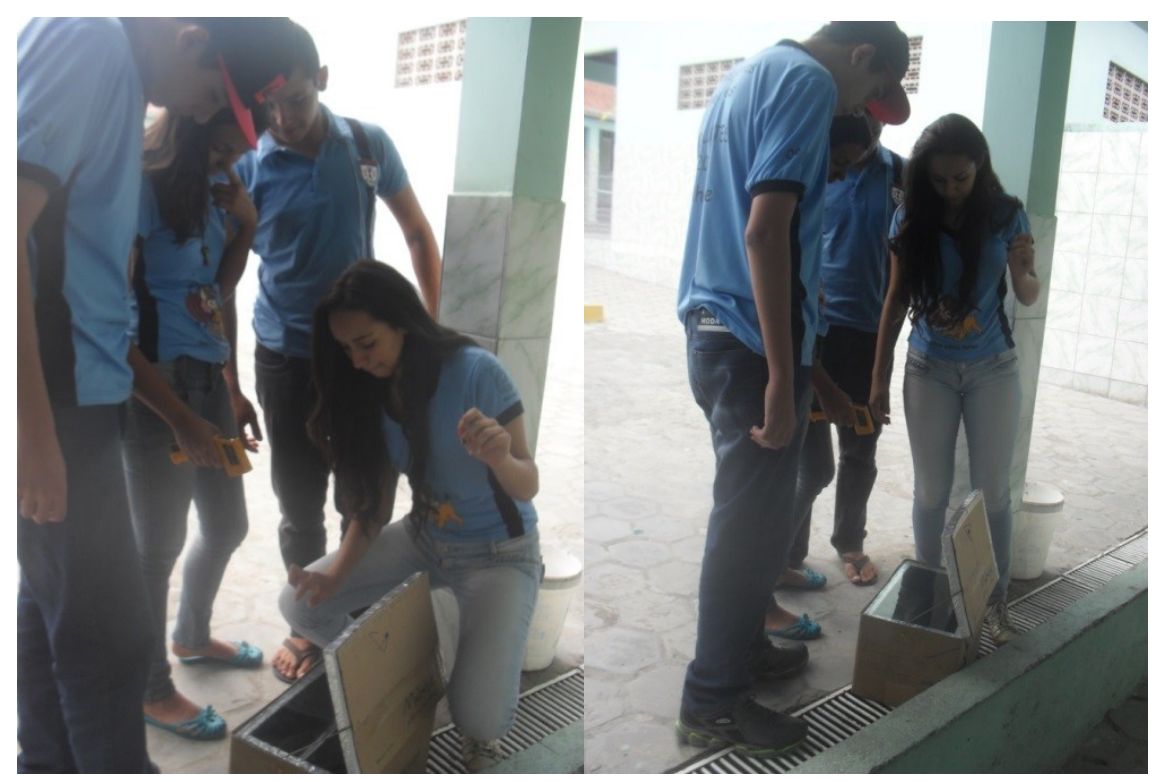

Figuras 3 e 4: Alunos Realizando as Aferições com um Termômetro. Fonte: Própria.

Indivíduos que aprendem de forma prazerosa aprendem mais eficientemente, para Lucie (2005), é preferível o ensino em forma dinâmica, ao invés de lecionar chateando o aluno, fazendo com que ele sinta um desprazer ao confrontar determinado conteúdo, desse modo podemos perceber que houve uma reação muito positiva quanto à metodologia apresentada ao alunado. A experimentação, a prática utilizada na intervenção pedagógica foi totalmente diferente e teve um 
formato novo para os alunos, o que facilitou muito a aplicação dos conteúdos de Termodinâmica trabalhados com alunos na realização da intervenção.

Trabalhando em números, após uma avaliação escrita ao final da intervenção pedagógica, relacionamos os conteúdos específicos trabalhados em sala de aula com o auxílio experimental, sendo assim, pode ser constatado que $80 \%$ dos alunos responderam de forma satisfatória todas as questões específicas que não necessitavam de alguma ferramenta matemática. Porém, parte do alunado sente algum tipo de dificuldade quanto à utilização do conteúdo da matemática e isto foi visto quando tratadas as questões que precisariam da mesma, para que pudessem ser resolvidas, como, por exemplo, o cálculo do calor sensível de $50 \mathrm{ml}$ de água antes e depois da aferição realizada por eles, o que foi uma aplicação simples do que pode ser observado no fogão solar. Logo, 66,6\% dos alunos responderam de forma completamente satisfatória todas as questões propostas que precisava ser aplicada matemática.

$\mathrm{Na}$ mesma avaliação, quando questionados de forma discursiva se a utilização do experimento melhorou a visualização dos conceitos, que geralmente são aplicados de forma clássica, e se a aplicação prática da física melhorou de alguma maneira o jeito com que eles viam a mesma. A resposta foi quase unânime: aproximadamente 93,3\% dos alunos responderam de forma positiva, sendo que, os que tiveram uma reação contrária afirmam que não sentem nenhum tipo de afinidade com a física, o que dificulta o gosto pela ciência.

Fazer uma investida no objeto concreto, segundo Moraes e Mancuso (2004), não quer dizer somente que irá atrair o aluno pelo simples fato de ser algo não visto no cotidiano escolar, mas a atividade experimental pode, sem dúvida, aproximar as várias vertentes do conhecimento do aluno. Além disso, a atividade prática relacionada não só a física, mas nas diversas áreas do conhecimento melhoram a visão do aluno quanto ao saber propriamente dito, promovendo o aprofundamento teórico do objeto estudado.

Observamos que os alunos, tendo facilidade de ver a aplicação do experimento conseguiram perceber como a física e a química podem ser bastante úteis no dia-a-dia, pois utilizando o fogão solar de forma prática podemos trabalhar os conceitos de calor, temperatura e as primeiras duas leis da Termodinâmica, da mesma forma que podemos trabalhar esses contextos de uma forma física, tal como utilizar o conceito de Entalpia do sistema de forma simples e atrativa, aplicando-as a um experimento de relativa facilidade de visualização, produção e acessível quanto a obtenção dos materiais utilizados. Por serem totalmente recicláveis, o custo de obtenção dos materiais necessários é quase nulo para a confecção e utilização do experimento. Fazer a Descrição dos dados obtidos e 
principais resultados, fazer relação entre os dados obtidos e as hipóteses de pesquisa, apresentar dados inesperados que apareceram e que acha interessante destacar. Interpretar os resultados e discutir tendo como base a fundamentação teórica.

Podemos também estabelecer uma ótima relação entre as duas partes estudadas a partir de um ponto de vista interdisciplinar, que conforme Olga Pombo et al.:

“[...] a interdisciplinaridade surge na escola, não como uma nova proposta pedagógica apresentada aos professores pelos pedagogos ou poderes centrais, mas como uma aspiração emergente no seio dos próprios professores. São os professores que, por sua iniciativa, vêm realizando, com uma frequência crescente, experiências de ensino que visam alguma integração dos saberes disciplinares e implicam algum tipo de trabalho de colaboração entre duas ou mais disciplinas. (POMBO, 1993, pg. 8)

Essa breve citação nos permite relacionar a experiência vivida na intervenção pedagógica com a literatura, uma vez que, os próprios licenciandos responsáveis pela criação e aplicação da prática pedagógica sentiram a necessidade de trabalhar os conceitos tanto químicos quanto físicos do experimento, realizando uma colaboração entre as duas áreas do conhecimento.

Para Fazenda (2003) ao construirmos pontes entre diferentes disciplinas, podemos permitir que o conhecimento transborde os limites impostos pelas próprias disciplinas envolvidas colocando a interdisciplinaridade como uma ação de permutação de saberes, diferenciando-a das disciplinas, que estariam categorizadas como conhecimento.

Conseguimos com isso estabelecer uma mesma visão para saberes diferentes, ligados a uma situação cotidiana, que conforme Foures (1995) a interdisciplinaridade nos propõe duas perspectivas, a primeira que está justamente no fato de que podemos estabelecer esses laços para uma mesma situação, tendo em vista uma nova maneira de resolução e representação do problema proposto, mais adequado de um ponto de vista absoluto, concreto, uma "superciência”; e uma segunda visão que nos permitiria estabelecer uma prática específica com o intuito de trabalharmos problemas encontrados no nosso cotidiano, que necessitam, geralmente, de mais de um ponto de vista, pois se busca o confronto entre perspectivas de especialistas vindos de diversas formações, nesta se encaixa a proposta do trabalho, onde podemos estabelecer algumas relações muito parecidas e efetivas para a explicação de um só experimento.

Conforme dos Santos et al. (apud Lenoir, 2011):

"Lenoir chama de interdisciplinaridade escolar, visando a conversação entre disciplinas escolares na educação básica. Há diferentes níveis de interações disciplinares expressos nos 
conceitos de Multidisciplinaridade, Pluridisciplinaridade e Transdisciplinaridade, de maneira que esses conceitos estariam em uma ordem crescente de maturidade, respectivamente.” (DOS SANTOS, 2011)

No caso da intervenção pedagógica aplicada, buscamos fugir da limitação imposta por cada uma das disciplinas trabalhadas. (PAVIANI, 2008, p.14)

\section{Conclusões}

Podemos, ao término desse trabalho, concluir que apesar de todas as adversidades quanto ao ensino de caráter ativo, de pesquisa, existem muitas possibilidades de criação de experimentos acessíveis a grande maioria das pessoas. Citamos como exemplo o experimento utilizado nesta intervenção pedagógica, o qual demonstrou satisfatoriamente que experimentos podem ser criados e utilizados em escolas que não têm possibilidade de conseguir experimentos muito complexos, como os encontrados no mercado.

A prática interdisciplinar por sua vez, nos deu bons frutos. Certamente, pelo menos em nosso contexto atual, não seria possível aplicar toda disciplina sem exceção de forma interdisciplinar, mas isso não impede que o professor, ou a instituição de ensino busque maneiras alternativas de realizar a prática, que no ponto de vista dos autores se encaixou perfeitamente com o tema proposto: utilizar um experimento a baixo custo de forma interdisciplinar.

Outro fato relevante para determinar a eficiência da intervenção pedagógica foi o levantamento quantitativo feito a partir da avaliação formal feita ao final da aula, visto que a maioria dos alunos respondeu de forma mais que aceitável as questões e problematizações propostas, o que nos levou a acreditar piamente no método interdisciplinar e experimental utilizado. Podemos concluir também que é extremamente relevante o fato de que novas ferramentas de ensino precisam ser desenvolvidas a cada dia para suprir a necessidade de adaptação à realidade atual do ensino.

A criatividade, o poder de ação, a pesquisa, a interação são itens que devem obrigatoriamente ser estimulados a todo instante pelo professor objetivando edificar a autonomia nos seus alunos. Dessa maneira a cada dia mais cidadãos saem totalmente capacitados da escola para as mais variadas áreas do conhecimento que dependem da qualidade do ensino, como as várias áreas que se utilizam da física. Portanto, para que se possa estabelecer uma base sólida de educação e formação de qualidade, seja simples, inter, multi ou transdisciplinar, precisamos como educadores, acima de tudo, colocar o aluno como centro das atenções e como objetivo principal do processo de 
ensino-aprendizagem para que a sociedade como um todo venha a colher os frutos desse processo em um futuro não tão distante.

\section{Referências}

ARAÚJO, Mauro S. T.; ABIB, Maria L. V. dos Santos. Revista Brasileira de Ensino de Física, vol. 25, no. 2, 2009.

BONATTO, A., BARROS, C. R., GEMELI, R. A., LOPES, T. B., \& FRISON, M. D. INTERDISCIPLINARIDADE NO AMBIENTE ESCOLAR. 2012.

DOS SANTOS, J. A. JUNIOR, L. P. C., Rui, N. \& BEJARANO, R. A Interdisciplinaridade no Ensino de Química. 2011.

FERNANDES, Fabiano A.N.. M. PIZZO, Sandro. MORAES JR., Deovaldo. TERMODINÂMICA QUÍMICA. 1 Ed. 2006.

FREIRE, Paulo. Educação como prática da liberdade. 17ª ed. Rio de Janeiro, Paz e Terra, 1979.

FREIRE, Paulo. Pedagogia do Oprimido. 13a .ed. Rio de Janeiro, Paz e Terra (Coleção O Mundo, Hoje,v.21), 1983.

HALLIDAY, David; RESNICK, Robert; WALKER, Jearl. Fundamentos De Física, Gravitação, Ondas e Termodinâmica. Vol. 2, pág. 183-200, 8ª ed. Rio de Janeiro: LTC Editora, 2009.

KAZUHITO, Yamamoto; FUKE, Luís Felipe. Física para o Ensino Médio, Termologia, Óptica e Ondulatória. Vol.2, pág. 10-108, 1ª ed. São Paulo: Editora Saraiva, 2010.

LUCIE apud CAD. BRÁS. ENS. FÍS. v.22, n.3: p.301-302, dezembro de 2005.

MATOS, Maria G.; VALADARES, Jorge. O Efeito da Actividade Experimental na Aprendizagem da Ciência Pelas Crianças do Primeiro Ciclo do Ensino Básico. Investigação em Ensino de Ciências, Rio Grande do Sul, v. 6, n. 2, p. 227-239, 2001.

MORTIMER, Eduardo Fleury. AMARAL, Luiz Otávio F. QUÍMICA NOVA NA ESCOLA Calor e temperatura no ensino de termoquímica. № 7, MAIO 1998.

PAVIANI, Jayme. Interdisciplinaridade: conceitos e distinções. 2. ed. Caxias do Sul, RS: Educs, 2008.

PIAGET, Jean; A Linguagem e o Pensamento da Criança. $3^{\text {a }}$ ed. Rio de Janeiro: Editora Fundo de Cultura, 1973.

POMBO, Olga. LEVY, Teresa. GUIMARÃES, Henrique. A Interdisciplinaridade: Reflexão e Experiência. Lisboa: ed. Texto, 1993. 
RAMOS, Luciana Bandeira da Costa; ROSA, Paulo Ricardo da Silva. O Ensino de Ciências: Fatores Intrínsecos e Extrínsecos que Limitam a Realização de Atividades Experimentais pelo Professor dos nos Iniciais do Ensino Fundamental. Investigação em Ensino de Ciências, Rio Grande do Sul, v. 13, n. 3, p. 299-331, 2008.

ROCHA FILHO, João Bernardes; BASSO, Nara Regina de Souza.; BORGES, Regina Maria Rabello. Transdisciplinaridade - a natureza íntima da educação científica. Porto Alegre: EDIPUCRS, 2007.

VILLANI, Carlos Eduardo Porto; NASCIMENTO, Silvania Sousa. A Argumentação e o Ensino de Ciências: Uma Atividade Experimental no Laboratório Didático de Física do Ensino Médio. Investigação em Ensino de Ciências, Rio Grande do Sul, v. 8, n. 3, p.187-209, 2003.

ZANON, Lenir B. \& SILVA, Lenice H. A. A Experimentação no Ensino de Ciências. In: SCHNETZLER, Roseli P., ARAGÃO, Rosália M. R. (org.) Ensino de Ciências: fundamentos e abordagens. Piracicaba: CAPES / UNIMEP, 120-53, 2000. 